\title{
Food surveillance and food safety
}

\section{By G. A. H. Elton, Ministry of Agriculture, Fisheries and Food, Horseferry Road, London $S W_{1} P_{2} A E$}

For the purpose of the present paper, food surveillance will be defined as the systematic determination of amounts of selected potentially toxic substances present in samples representative of individual foodstuffs or of total diets, either nationally or locally. Food surveillance is normally undertaken to provide a factual basis for the assessment, by expert committees, of any possible hazard to the consumers' health from the consumption of such foodstuffs.

The average person in the United Kingdom eats about $1.5 \mathrm{~kg}$ of food per day, i.e., approximately 0.5 tonne per year. Food and drink account for $30 \%$ of consumer expenditure in the United Kingdom and of this expenditure, only about a quarter is on fresh food, the remaining three-quarters being on food and drink processed to a greater or lesser extent.

The United Kingdom imports about $45 \%$ of its total food supplies. Some of these imports, equivalent to about $18 \%$ of our food supplies, are of foods such as maize, soya, oils and oil seeds, citrus fruits, coffee and tea, which are not suitable for commercial production in the United Kingdom. In considering food surveillance and food safety, we are dealing, therefore, not only with food produced in the United Kingdom, and containing contaminants of United Kingdom origin, but also possibly contaminated materials coming from abroad.

\section{Some possible hazards from food}

It would be wrong to suppose that all 'natural' foods are safe, and that possible hazards arise only from additives and contaminants. Many foods contain small amounts of natural poisons (National Academy of Sciences, I973); examples of these include lathyrogens and favism-inducers in certain legumes, goitrogens in brassicae, neurotoxins in certain shellfish, etc.; gluten proteins from wheat produce ill effects in individuals who suffer from coeliac disease; and so on. Most people consuming moderate amounts of common foods are capable of dealing with traces of potentially toxic substances by various detoxification mechanisms in the body. However, it is always possible that some people may experience adverse reactions when a new food is introduced into their diet, or that new varieties of established food plants may contain higher amounts of potentially toxic substances than usual, and may need to be withdrawn or controlled by regulation (ARC/MRC, 1974).

Some contaminants of food are also of natural origin, e.g. bacteria, bacterial toxins, moulds, mycotoxins, etc. Other contaminants can include heavy metals, 
animal feed additives and growth promoters, pesticide residues, oil and petroleum derivatives, polychlorinated biphenyls, nitrates and nitrites, packaging migrants, asbestos, etc.

Increased industrial activity often leads to increased environmental pollution, which in turn can lead to increased contamination of food. Although materials from the environment which potentially present a toxic hazard may enter the human body by a number of routes, e.g., through the skin, the lungs or the alimentary tract, it is known that for many the latter is the major route and that food and drink are the main vehicles. For example, while those people suffering from clinical lead poisoning are almost invariably receiving most of their lead intake from other sources, e.g. industrial exposure, pica, drinking water in contact with lead pipes or lead storage tanks, etc., the majority of the lead taken in by the ordinary person comes from food.

\section{Food additives}

Substances deliberately added to food for some technological purpose may also present some risk to the consumer. However, in the United Kingdom and in most other advanced countries, the use of food additives is subject to close legislative control. All candidates for inclusion on one of the permitted lists of additives in the United Kingdom must be supported by comprehensive data on safety and need, which are evaluated by the Toxicity Sub-Committee (TSC) of the Committee on Medical Aspects of Chemicals in Food and the Environment, and by the Food Additives and Contaminants Committee (FACC) of MAFF. The main concern nowadays is not over additives which might present an acute toxic hazard, these are fairly easy to eliminate, but over possible long-term effects, particularly carcinogenicity, of small quantities of a substance ingested regularly over many years. In the present state of knowledge on carcinogenicity, and on the extrapolation of animal data to man, this is a difficult field.

Experiments on large numbers of laboratory animals may be necessary, particularly to demonstrate weak carcinogenic properties in a chemical compound. Tests, therefore, tend to be done at very high dose levels in the hope of obtaining statistically significant results with a reasonable number of animals; this sometimes leads to the feeding of such vast quantities of an additive, usually used only in trace amounts, that normal pathways of metabolism may be swamped and abnormal metabolites may cause toxic effects which would not occur under usual conditions of usage. However, the purpose of the present paper is not to consider substances which are deliberately added to food and therefore open to direct scrutiny and legislative control, but rather materials which find their way into food accidentally, and for which food surveillance is necessary.

\section{Food surveillance: chemical contaminants}

In the United Kingdom, the Interdepartmental Steering Group on Food Surveillance co-ordinates all work on the surveillance of food for chemical contaminants. It operates through a number of working parties dealing with 
groups of contaminants such as heavy metals, pesticides, packaging migrants, etc., and submits its results for evaluation to the TSC and the FACC. In assessing the possible effects on health of a particular contaminant in food, it is necessary to have information on (a) probable intake of the contaminant from food and other sources by the average consumer; (b) foods particularly at risk; (c) any special groups of consumers who may be at risk because of special eating habits; (d) potential toxicity of the contaminant, assessed by biological studies.

The probable intake from food by the average consumer is usually assessed by a Total Diet Study. This method was first introduced in 1966 to obtain information about the intake of pesticide contaminants from the diet as a whole for the average person in the United Kingdom, and is now used for a wide range of food contaminants. Almost all the foods of the average diet are sampled, and where appropriate prepared as for consumption in nine composite groups, namely, cereals, meat, fish, fats and oils, fruit and preserves, root vegetables, green vegetables, milk, and beverages. The weight of the different food within the groups reflects their relative proportions in the average diet, and samples made up in this manner are obtained from about eighteen of the main towns throughout the United Kingdom. The groups are separately analysed, the mean contaminant concentration determined, and the average daily intake of the contaminant estimated on the basis of food consumption data from the National Food Survey. During the past few years reports have been published by the Working Party for the Monitoring of Foodstuffs for Heavy Metals on mercury (1971, 1973), lead (1972, 1975) and cadmium (1973). Table I gives, as an example, the results for the $\mathrm{Pb}$ content of the average diet in $197^{1-72}$, determined in this way.

Table I. Average daily intake of lead"

$\begin{array}{lccc} & \begin{array}{c}\text { Mean lead } \\ \text { content } \\ (\mathbf{m g} / \mathbf{k g})\end{array} & \begin{array}{c}\text { Estimated } \\ \text { weight eaten } \\ (\mathbf{k g})\end{array} & \begin{array}{c}\text { Average intake } \\ (\mu \mathrm{\mu g} / \text { person } \\ \text { per day) }\end{array} \\ \text { Cereals } & 0.17 & 0.27 & 46 \\ \text { Meat and fish } & 0.17 & 0.18 & 3 \mathrm{I} \\ \text { (Fish) } & (0.08) & & \\ \text { Fats } & 0.08 & 0.08 & 6 \\ \text { Fruits and preserves } & 0.12 & 0.25 & 30 \\ \text { Root vegetables } & 0.20 & 0.21 & 42 \\ \text { Green vegetables } & 0.24 & 0.11 & 26 \\ \text { Milk } & 0.03 & 0.40 & 12 \\ \text { Total } & 0.13 & 1.5 & \text { about 200 }\end{array}$

-Also, approximately $20 \mu \mathrm{g} /$ person per $\mathrm{d}$ from beverages.

The diet of individual people may depart widely from the average diet, and some may be particularly at risk if they eat large quantities of a food containing a specific contaminant. For example, it was found that the $\mathrm{Pb}$ content of canned baby foods, although well below the legal limit of $2 \mathrm{mg} / \mathrm{kg}$, averaged $0.24 \mathrm{mg} / \mathrm{kg}$ compared with the average of $0.13 \mathrm{mg} / \mathrm{kg}$ for the national diet as a whole. Canned baby foods 
may form a major part of the diet of some infants and young children, and as the weight of food ingested by children per $\mathrm{kg}$ body-weight is greater than that ingested by adults, the intake of dietary $\mathrm{Pb}$ per kg body-weight would also be higher. For this reason, although there was no evidence of harm to health of children, it was thought prudent to reduce the amount of $\mathrm{Pb}$ in canned baby goods. The manufacturers of these products altered their canning technology, and new legislation was introduced on I January 1973 , lowering the permitted maximum amount of $\mathrm{Pb}$ in baby foods from $2 \mathrm{mg} / \mathrm{kg}$ to $0.5 \mathrm{mg} / \mathrm{kg}$. When the next survey was published in 1975 , the average lead content of canned baby foods had been reduced by a factor of about 3, to $0.07 \mathrm{mg} / \mathrm{kg}$, i.e., well below the $\mathrm{Pb}$ content of the national diet as a whole.

Estimates of the weekly intake of $\mathrm{Pb}$ from food and beverages by adults in the United Kingdom were $1.5 \mathrm{mg}$ in 1972 and $\mathrm{I} \mathrm{mg}$ in 1975 ; these figures may be compared with the maximum tolerable intake of $3 \mathrm{mg} /$ person per week suggested by WHO. Partly as a result of the surveys described, the FACC has recommended that the maximum amount of $\mathrm{Pb}$ permitted in most foods should be reduced from $2 \mathrm{mg} / \mathrm{kg}$ to $\mathrm{I} \mathrm{mg} / \mathrm{kg}$.

As far as some other heavy metals are concerned, fish is the main dietary source of $\mathrm{Hg}$ (Working Party on the monitoring of Foodstuffs for Heavy Metals, 197I, 1973a), particularly in the highly toxic methylmercury form, while $\mathrm{Cd}$ is particularly high in the brown meat of crabs and in certain shellish (Working Party on the monitoring of Foodstuffs for Heavy Metals, 1973b). Other studies on arsenic, zinc, selenium, copper, manganese, polychlorinated biphenyls and other contaminants are in hand.

To quote one further example, a survey for volatile nitrosamines has been undertaken on the components of the United Kingdom diet (Report of the Government Chemist, 1973). Nitrosamines, which can be formed by reaction between nitrites and secondary amines under appropriate conditions, are carcinogenic to experimental animals when fed in fairly high doses (e.g., I mg/kg). However, even with methods sensitive to less than $1 \mu \mathrm{g} / \mathrm{kg}$ they are not found in most foods; small amounts of $\mathrm{N}$-nitrosopyrolidine are found in cooked bacon, possibly arising from the nitrite added in the curing process. However, the total amount of volatile nitrosamines in the average British diet is probably of the order only of I $\mu \mathrm{g} / \mathrm{kg}$. The significance of this to human health is not known, but on the advice of the FACC and the TSC (FACC, I962) a comprehensive programme of research designed to improve our knowledge in this field is in hand. There is no evidence that these small amounts of nitrosamines cause any harm to man, and it would certainly be unwise to attempt to eliminate nitrosamines from the diet by banning the use of nitrites in cured meats, as they perform an invaluable function in preventing the formation of botulinum toxin in such foods.

\section{Food surveillance: microbial contaminants}

In 1974, 7295 cases of food poisoning were notified in England and 4I people died (Chief Medical Officer, 1974). Virtually all of these cases were due to 
microbial contamination arising from poor hygiene and bad food handling practices, and over half $(56 \%)$ were due to Salmonella food poisoning. Foods may become contaminated with micro-organisms in various ways. Food animals may themselves be diseased or be carriers of infection. Micro-organisms may be concentrated or proliferate in fish, shellfish, vegetables, water, and other raw materials and create a toxic or infective hazard. Contamination may occur during food processing and distribution, and in the kitchen, including contamination from human sources, vermin or cross-infection from ingredient materials.

With few exceptions (e.g., in the Regulations on UHT milk), no quantitative statutory requirements are laid down in the United Kingdom legislation for the bacteriological composition of food. The onus for ensuring that food is fit for human consumption is placed on the producers of food, food manufacturers and retailers, who are required to supply food which complies with the Food and Drugs Act 1955. Authorized officers of the Local and Port Health Authorities have considerable professional discretion in sampling and testing, and have powers to seize food as unfit for human consumption. In cases of dispute, a court of law has power to decide. Food may also be sampled as part of an epidemiological investigation into the spread of food poisoning. Incidents of Salmonella food poisoning due to exotic serotypes increased sharply between 1966 and 1970, during which period the incidents involving poultry meat increased by a factor of three. Epidemiological investigations produced evidence suggesting a direct link between imported animal feeds containing these exotic serotypes, contaminated birds on the farm and poultry carcases in packing plants, and the causative organism of human food poisoning. This cycle of infection is most readily broken at the point of feedstuffs manufacture, hence impending legislation (the Protein Processing Order) requiring the sterilization of protein of animal origin recycled as feed. Furthermore, the Zoonoses Order 1975 makes available powers to investigate and control Salmonella and Brucella infections in animals and Salmonella infections in birds which present a threat to human health.

From time to time particular foodstuffs which are known to present microbiological problems are sampled more intensively, as part of a planned programme of surveillance, with the intention of applying remedial action at source where necessary. For example, at one time desiccated coconut, which was infected with Salmonella organisms, was so sampled, and the results led to the enforcement of improved hygiene measures in the country of origin. At another time, there was a major programme of surveillance for Salmonella organisms in liquid whole egg used by the baking industry. The results obtained, particularly with some samples of imported liquid whole egg, led to the enactment of regulations which make compulsory the pasteurization of liquid whole egg under specified conditions.

The possibility of laying down microbiological standards for foodstuffs has been widely discussed in many countries and in the EEC. Although the approach of setting quantitative standards is appropriate to many chemical contaminants of food, such substances are usually susceptible to relatively exact chemical or physical analysis. They are usually distributed through the bulk of the food, the 
levels determined can often be correlated directly with the hazard to health, and the quantity found will not vary substantially with time. These conditions do not generally apply to microbiological contamination, and the general view of the United Kingdom Government is that the random testing of foods for pathogenic micro-organisms offers little protection against food-borne diseases. When a microbiological standard is being contemplated for a food, it is necessary to consider (a) the purpose for which the test is carried out; (b) the stage, scale, and frequency of sampling; (c) the methodology to be used in the laboratory; (d) the tolerance, or lack of it, to be applied to the results; and (e) interpretation of the results and action to be taken.

Microbiological standards should be simple, practical, limited in number, economically feasible in regard to staff, facilities and time, and capable of implementation. The alternative approach, favoured in the United Kingdom, is to reduce food poisoning and raise standards of food hygiene and safety by education and by informed inspection of the various stages of food processing. It is a fairly readily accepted tenet of microbiology that the safety of the process can be assured only by attention to the process, not by examination of the end-product.

Toxic metabolites of moulds, mycotoxins, have received increasing attention in recent years. The last outbreak of ergotism in humans, caused by the ingestion of ergot produced by Claviceps purpurea on rye grain, occurred in France in $195 \mathrm{I}$; no case has been observed in the United Kingdom since the 1920s. A large new group of carcinogenic mycotoxins has been discovered since the first work on aflatoxins in the early 1960s. Aflatoxin is a potent liver carcinogen in experimental animals. It can be detected in some samples of groundnut meal infested with certain strains of Aspergillus flavus. No direct relationship between the occurrence of aflatoxin in foods and the incidence of cancer in humans has been proved, although some epidemiological evidence for a correlation between the consumption of groundnuts and the incidence of liver cancer in parts of Africa has been obtained. So far as is known, the major mycotoxins occur mainly in tropical or sub-tropical foodstuffs, and materials which might be infected, especially groundnuts, are inspected at ports and sub-standard batches are condemned. In 1973, 13\% of all groundnut imports into the United Kingdom were found to contain aflatoxin in amounts exceeding $50 \mu \mathrm{g} / \mathrm{kg}$, and were not used for human food. No aflatoxin was found in a limited survey of imported cheeses and full cream dried milks. The Interdepartmental Steering Group on Food Surveillance is at present reviewing mycotoxins in food in the United Kingdom, and examining the need for additional monitoring of foodstuffs.

\section{Conclusions}

It is always necessary to keep a sense of proportion about the risks to health arising from food. There is risk associated with every human activity, and the number of deaths known to be caused by food poisoning every year is very small compared with deaths from road accidents or from accidents in the home. However, food has a special place in our minds and the public understandably 
tends to view hazards from food with more emotion than those from other human activities. Many of the toxic hazards which plagued the national food supply 100 years ago have been eliminated, and the regular surveillance of food for potentially hazardous substances is part of the continuing work to improve the situation still further.

The practical value of surveillance procedures depends greatly on the type of contaminant present. As a generalization, total diet studies and routine monitoring of food samples for chemical contaminants have often proved valuable in the past and are continuing to do so; in some cases, however, our ability to detect minute traces of some chemical contaminants has outstripped our ability to interpret the significance, if any, of the findings to human health. The problems facing the TSC and the FACC are not easy ones, but these Committees play an important part in safeguarding public health in this country.

Methods of assessment of contamination of foodstuffs by pathogenic microorganisms are often less satisfactory than those for chemical contaminants. Nonetheless, monitoring as practised by Health Authorities, and epidemiological surveys carried out by the Public Health Laboratory Service and by research microbiologists have identified particularly troublesome sources of food poisoning. The most effective control in the interests of consumer protection is exercised not by use of legal standards and end-product sampling, but by legal requirements or codes of practice for adequate processing and regular quality control checks by the processor.

\section{REFERENCES}

'Toxicants Occurring Naturally in Foods'. National Academy of Sciences, Washington, USA, 2nd Edition, 1973 .

'Food and Nutrition Research'. Report of the ARC/MRC Committee p. 171, HMSO, 1974.

Working Party on the Monitoring of Foodstuffs for Mercury and Other Heavy Metals (1971). First Report: Survey of Mercury in Food London: HM Stationery Office.

Working Party on the Monitoring of Foodstuffs for Heavy Metals (1973). Third Report: Survey of Mercury in Food: A Supplementary Report London: HM Stationery Office.

Working Party on the Monitoring of Foodstuffs for Heavy Metals (1972). Second Report: Survey of Lead in Food London: HM Stationery Office.

Working Party on the Monitoring of Foodstuffs for Heavy Metals (1975). Fifth Report: Survey of Lead in Food: First Supplementary Report London: HM Stationery Office.

Working Party on the Monitoring of Foodstuffs for Heavy Metals (1973). Fourth Report: Survey of Cadmium in Food HMSO 1973.

Report of the Government Chemist (1973). pp. 43-47. London: HM Stationery Office.

FACC (1962). Report on the Review of Preservatives in Food Regulations pp. 72-73. London: HM Stationery Office.

Chief Medical Officer (1974). Department of Health and Social Security Annual Report. Iondon: HM Stationery Office.

The Zoonoses Order (1975). SI No. 1030. London: HM Stationery Office. 